\title{
Clinicopathological comparisons of open vein harvesting and endoscopic vein harvesting in coronary artery bypass grafting patients in Mashhad
}

\author{
Ahmad Amouzeshi ${ }^{1}$, Mohamad Abbassi Teshnisi ${ }^{2}$, Nahid Zirak ${ }^{3}$, Alireza Sepehri Shamloo ${ }^{4}$, Hamid \\ Hoseinikhah $^{5}$, Behzad Alizadeh ${ }^{6}$, Aliasghar Moeinipour ${ }^{7}$
}

${ }^{1}$ M.D., Assistant Professor, Department of Cardiac Surgery, Faculty of Medicine, Birjand University of Medical Science, Birjand, Iran

${ }^{2}$ M.D., Associate Professor, Department of Cardiac Surgery, Faculty of Medicine, Atherosclerosis Prevention Research Center, Imam Reza Hospital, Mashhad University of Medical Science, Mashhad, Iran

${ }^{3}$ M.D., Associate Professor, Department of Anesthesiology, Faculty of Medicine, Imam Reza Hospital, Mashhad University of Medical Science, Mashhad, Iran

${ }^{4}$ Medical Student, Student Research Committee, Mashhad University of Medical Sciences, Mashhad, Iran

${ }^{5}$ M.D., Assistant Professor, Department of Cardiac Surgery, Atherosclerosis Prevention Research Center, Imam Reza Hospital, Mashhad University of Medical Science, Mashhad, Iran

${ }^{6}$ M.D., Assistant Professor, Department of Pediatric Cardiology, Faculty of Medicine, Imam Reza Hospital, Mashhad University of Medical Science, Mashhad, Iran

${ }^{7}$ M.D., Assistant Professor, Department of Cardiac Surgery, Faculty of Medicine, Atherosclerosis Prevention Research Center, Imam Reza Hospital, Mashhad University of Medical Science, Mashhad, Iran

\section{Type of article: Original}

\begin{abstract}
Introduction: Harvesting of the greater saphenous vein is almost an inevitable part of coronary artery bypass grafting $(\mathrm{CABG})$ operations, and it is done by two main techniques, i.e., conventional or open vein harvesting $(\mathrm{OVH})$ and the minimally-invasive endoscopic vein harvesting $(\mathrm{EVH})$. This study aimed to compare these two techniques in off-pump $\mathrm{CABG}$ procedures with respect to clinical and pathological outcomes.

Methods: This cohort study was conducted on CABG candidates during a one-year period from October 2013 through September 2014 in the Department of Cardiac Surgery at Mashhad University of Medical Sciences. Eighty-seven patients voluntarily underwent $\mathrm{EVH}$, and another 86 patients matched for age, gender, and other cardiovascular risk factors were selected for OVH. They were followed up for six weeks, and the main outcome measures were infections of the wound, pain, duration of hospital stay, and the costs of hospitalization. Paired sample t-test, independent t-test, or their non-parametric equivalents and the chi-squared test were used by SPSS version 17.0 for data analysis.

Results: The mean duration of time for vein harvesting was shorter in the EVH group $(p<0.001)$, and the pain score was lower $(\mathrm{p}=0.04)$. No infections occurred at the site of the wound. The length of hospital stay was not significantly different for the two groups (OVH versus EVH: $8.5 \pm 3.3$ versus $8.4 \pm 3.2$ days; p-value: 0.08 ). Hospitalization costs were significantly higher in the EVH group (OVH versus EVH: $5.8 \pm 4.7$ versus $7.3 \pm 2.0$ million Tomman; $p$-value: 0.008 ), yet no difference was diagnosed with respect to endothelial damage in the vein grafts harvested by the EVH and OVH techniques.

Conclusion: EVH is considered as a minimally invasive and safe vein harvesting technique in our Center, and it can reduce the harvesting time and post-operative pain. In addition, its efficiency was similar to that of OVH.

Keywords: endoscopic vein harvesting, open vein harvesting, coronary artery bypass grafting, graft patency, clinical outcome, pathological outcome
\end{abstract}

\section{Corresponding author:}

Assistant Professor Dr. Aliasghar Moeinipour. Department of Cardiac Surgery, Faculty of Medicine, Atherosclerosis Prevention Research Center, Imam Reza Hospital, Mashhad University of Medical Science, Mashhad, Iran.

Tel: +98.5138022321, Fax: +98.5138525307, Email: moinipoora1@mums.ac.ir

Received: September 23, 2015, Accepted: November 27, 2015, Published: January 2016

iThenticate screening: November 04, 2015, English editing: January 03, 2016, Quality control: January 06, 2016

(C) 2015 The Authors. This is an open access article under the terms of the Creative Commons Attribution-NonCommercialNoDerivs License, which permits use and distribution in any medium, provided the original work is properly cited, the use is non-commercial and no modifications or adaptations are made. 


\section{Introduction}

The greater saphenous vein (GSV) remains the most commonly harvested conduit for revascularization in coronary artery bypass grafting $(\mathrm{CABG})(1,2)$. The conventional technique for this procedure has long been open vein harvesting $(\mathrm{OVH})$. Several studies have reported that the $\mathrm{OVH}$ technique results in post-operative pain, delayed healing, and prolonged hospital stay (3-5). Therefore, in the past decade, a minimally invasive technique has been developed to reduce the surgical trauma associated with $\mathrm{OVH}$ and improve patients' satisfaction without disturbing the post-surgical outcomes (3-5). There is strong evidence to suggest that the endoscopic vein harvesting (EVH) technique can reduce post-operative infections, pain, mobility restriction, and the duration of hospital stays (6). In preliminary studies, no significant differences in graft patency were observed between the OVH and EVH techniques within six months of the procedures (7). However, in recent studies, it has been suggested that EVH may be accompanied by reduced graft patency (6). From the histological perspective, EVH has been proven to be very similar to the OVH technique; yet certain studies focusing on changes in the endothelial cellular surface are inconsistent with these findings. In a recent study, EVH was associated with a higher rate of venous graft failure and higher rates of mortality, myocardial infarction, and the need for revascularization during the first year after the surgery (3).

Since post-op angiographic studies are not routinely performed, we decided to perform this study on elective, offpump CABG candidates who made their own decisions to undergo the techniques. The aim of this study was to compare the clinical and pathological outcomes of OVH and EVH in patients who underwent the coronary artery bypass grafting procedure. In addition to the clinical and pathological outcomes, we compared the mean fees for the hospital stays for the EVH and OVH groups.

\section{Material and Methods}

\subsection{Study setting}

In this cohort study performed from October 2013 through September 2014, all patients scheduled for off-pump CABG in the Cardiac Surgery Ward of Imam Reza Medical were enrolled. Those undergoing CABG for the first time entered either the OVH group ( 86 cases) or EVH group (87 cases) based on their own decision-making. Patients were included in this study if they were more than 18 years old and scheduled for an elective off-pump CABG for the first time. Patients who also were also candidates for heart-valve surgery, had leg or other ulcers, had active bacterial infections, had simultaneous EVH and OVH, and those who died during surgery were excluded from the study. All operations were performed by a well-experienced surgeon in a single, well-equipped center. The aim of surgery was to obtain complete revascularization by using the graft obtained from the great saphenous vein or the left internal mammalian artery. The anesthesia protocol was similar for all subjects.

\subsection{Endoscopic vein harvesting technique}

EVH was performed in group A using the Vaso-View system (Open carbon dioxide $\left(\mathrm{CO}_{2}\right)$, Sorin Group Co). Dissection and visualization are possible in this exclusive technique in the presence of $\mathrm{CO}_{2}$. Provision of cases was the same with peripheral readiness in order to open harvesting. Openings were performed in the center on the upper and/or the bottom part of the knee through a small cut of 1.5 to $2.5 \mathrm{~cm}$, in accordance with the required length of selected vein; cutting was not done in the region of the knee flexor. Harvesting was conducted primarily to the groin region in order to get the enough vessel length (24). Bipolar cauterizing scissors were used for splitting the lateral branches when the peripheral vein was removed. A small cut was made close to the origin on the basis of endoscopic vision on saphenous vein to seal, freeze, and split the vessel for removal and preparation. After that, the lateral branches were closed and 7-0 monofilament prolene sutures were used, if required. Endoscopic dissection was done beneath the leg away from the center when an extra length of vessel was required. Typically, two or three pieces of the saphenous vein can be removed with each measuring about $15 \mathrm{~cm}(24)$. The lesions of the leg were examined closely for any bleeding, and they were kept open to reverse the effects of heparin. The removed regions were rubbed lightly in order to detect any bleeding or clotting, and, then, absorbable subcutaneous and subcuticular sutures were used to close the area. The wound was bandaged with elastic ACE ${ }^{\text {TM }}$ wrapfor 48 hours without draining.

\subsection{Open operative Technique of vein harvesting $(\mathrm{OVH})$}

Group B patients underwent conventional open vein harvesting. Long cutting were carried out in the saphenous vein area depending on the required number and length of vein grafts (24). When the vessel was visible, lateral branches were closed or clipped on both the case side and the graft side. Bipolar cauterizing scissors was used to divide the 
vein branches. The open leg wound was checked for hemostasis (24). The incisions were closed in layers by absorbable sutures and then ended by a subcuticular closure. Finally, the wound was wrapped with cotton gauze, and an ACETM wrap was applied to the entire leg for 48 hours. The open leg wound is then checked for hemostasis and irrigated with saline solution.

\subsection{Studied variables}

Demographic data, such as age, gender, body mass index (BMI), positive medical history of chronic obstructive pulmonary disease (COPD), asthma, transient ischemic attack (TIA), and diabetes were mentioned in each patient's history. Then, echocardiographic reports for ventricular ejection fraction (EF \%), baseline serum creatinine (mg/dL), and hematocrit levels $(\%)$ were recorded for all patients. Then we recorded the circumference $(\mathrm{cm})$ of the ankle of the target leg for harvesting leg, and pre-operative intra-aortic balloon pump (IABP) use was recorded. During the surgery, the mean duration ( $\mathrm{min}$ ), the mean blood products required during the operation, and the mean number of grafts performed were entered on the patients' records for both groups. Surgical outcomes were the length of the incision on the leg $(\mathrm{cm})$, the mean harvesting time $(\mathrm{min})$, and the length of the harvested vein $(\mathrm{cm})$. During the surgery, a specimen of the harvested vein was sent for pathological examination. Patients were followed up on the second day of their stay in the post-surgical intensive care unit (ICU) and on the last day of their stay in the postsurgical ward. Also, all patients were monitored for six weeks. ICU and ward observed clinical outcomes were as follows: the circumference $(\mathrm{cm})$ of the ankle of the harvesting leg, pain score (by visual analog scale), serum albumin level $(\mathrm{mg} / \mathrm{dL})$, serum creatinine level $(\mathrm{mg} / \mathrm{dL})$, positive troponin levels $(\mathrm{n})$, number of transfusion blood pack cells, cardiac arrhythmia, cerebrovascular accident (CVA), IABP use, re-operation rate, and death rate. Mean hospital stay and the fees for the hospital stays also were compared for the two groups. All patients were monitored for six weeks for the circumference of the ankle of the leg of harvested vein, the pain score, and the rate of wound infections.

\subsection{Research ethics}

The study protocol was approved by the Ethics Committee of Mashhad University of Medical Sciences and described to all patients. An informed consent was taken from each participant prior to entering the study.

\subsection{Statistical analyses}

SPSS version 17.0 (SPSS, Inc., Chicago, Illinois, United States of America) software was used to analyze the data. The paired sample t-test, the independent t-test, their non-parametric equivalents, and the chi-squared test were used as appropriate. The significance level was set at $\mathrm{p}<0.05$.

\section{Results}

\subsection{General findings}

In total, 173 patients were studied. The demographic characteristics of the two groups as they entered the study are provided in Table 1. Para clinic studies, including ventricular ejection fraction (EF \%) (OVH vs. EVH: $44.3 \pm 11.6$ vs. $50.5 \pm 12.1 ; \mathrm{p}=0.092)$, serum creatinine $(\mathrm{mg} / \mathrm{dL})(\mathrm{OVH}$ vs. EVH: $1.1 \pm 0.7$ vs. $1.1 \pm 0.4 ; \mathrm{p}=0.625)$, and hematocrit levels (\%) (OVH vs. EVH: 40.54 .9 vs. $38.1 \pm 4.8 ; \mathrm{p}=0.312)$ on the pre-op day showed no significant difference between the two groups. Moreover, the two groups of OVH and EVH were similar regarding the mean duration of surgery $(\mathrm{min})(\mathrm{OVH}$ vs. $\mathrm{EVH}: 263.2 \pm 66.3$ vs. $256.8 \pm 60.4 ; \mathrm{p}=0.412)$ and the mean blood products required during the operation (n) $(\mathrm{OVH}$ vs. $\mathrm{EVH}$ : $1.0 \pm 1.3$ vs. $1.0 \pm 1.2 ; \mathrm{p}=0.734)$. Among the 173 patients who underwent $\mathrm{CABG}, 584$ grafts were performed with a mean number of 3.37 grafts per patient, indicating no meaningful difference between the OVH and EVH groups (OVH vs. EVH: $3.2 \pm 0.7$ vs. $3.4 \pm 0.6 ; \mathrm{p}=0.061$ )

\subsection{Comparison of surgical outcomes}

The lengths of the incisions in the legs of the EVH group were significantly less than those in the OVH group, showing a meaningful difference $(3.719 \pm 3.66$ vs. $16.963 \pm 45.92 \mathrm{~cm}, \mathrm{p}<0.001)$. The mean harvesting time also was significantly less in the EVH group than in the OVH group $(16.518 \pm 36.55$ vs. $23.680 \pm 56.57 \mathrm{~min}, \mathrm{p}<0.001)$. Accordingly, the length of the harvested vein in the EVH group was less than that in the OVH group (14.440 \pm 35.59 vs. $15.932 \pm 44.47, \mathrm{p}=0.009)$. The most common locations for vein harvesting in both groups were above and below the knee ( $86.46 \%$ vs. $86.40 \%)$. However, in the OVH group, the most commonly used location was below the knee, whereas it was above the knee in the EVH group, showing a meaningful difference $(p=0.01)$. 
3.3. Comparison of post-op complications in the ICU and during hospitalization in the cardiac surgery ward In the ICU, no significant difference was found between the EVH and OVH groups considering the studied variables in their post-op ICU stay (Table 2). During hospitalization in the cardiac surgery ward, no significant difference was found between the two groups considering the studied variables in post-op ward stay (Table 3). The only difference between the two groups at the end of hospital stay was the hospital fees (Table 3).

\subsection{Six-week follow-up outcomes}

In the sixth post-op week, the circumference $(\mathrm{cm})$ of the ankle of the leg of harvested vein (OVH vs. EVH: $23.7 \pm$ 1.5 vs. $23.4 \pm 1.4 ; \mathrm{p}=0.309$ ) showed no meaningful difference between the two groups. Pain score was significantly less in the EVH group than in the OVH group $(\mathrm{OVH}$ vs. EVH: $1.3 \pm 0.8$ vs. $0.9 \pm 1.08 ; \mathrm{p}=0.02)$. Also, no cases of wound infection were observed in either group.

\subsection{Pathological outcome}

The vein grafts taken in the two groups showed no meaningful difference regarding their pathologic status based on endothelia injury (OVH vs. EVH: $2.3 \%$ vs. $0.0 \% ; \mathrm{p}=0.241)$ and intimal fibrosis (OVH vs. EVH: $8.1 \%$ vs. $2.3 \% ; \mathrm{p}$ $=0.091)$.

Table 1. Demographic characteristics of the OVH and EVH groups at study entrance

\begin{tabular}{|c|c|c|c|c|}
\hline \multicolumn{2}{|c|}{ Variable } & $\mathrm{OVH}^{*}(\mathrm{n}=86)$ & $\mathrm{EVH}^{* *}(\mathrm{n}=87)$ & p-value \\
\hline \multicolumn{2}{|l|}{ Age (yrs) } & $59.98 \pm 10.49$ & $59.36 \pm 8.207$ & 0.665 \\
\hline \multirow[t]{3}{*}{ Body Mass Index } & Normal & $43.5 \%$ & $40.5 \%$ & \multirow[t]{3}{*}{0.969} \\
\hline & Overweight & $40 \%$ & $41.7 \%$ & \\
\hline & Obese & $15.3 \%$ & $15.5 \%$ & \\
\hline \multirow[t]{2}{*}{ Sex } & Male & $62.4 \%$ & $65.5 \%$ & \multirow[t]{2}{*}{0.666} \\
\hline & Female & $37.6 \%$ & $34.5 \%$ & \\
\hline \multicolumn{2}{|l|}{ COPD } & $1.2 \%$ & $1.1 \%$ & 1.00 \\
\hline \multicolumn{2}{|l|}{ Asthma } & $2.3 \%$ & $3.4 \%$ & 1.00 \\
\hline \multicolumn{2}{|l|}{ Smoking } & $33.7 \%$ & $31 \%$ & 0.706 \\
\hline \multicolumn{2}{|c|}{ Transient Ischemic Attack } & $16.3 \%$ & $4.7 \%$ & 0.023 \\
\hline \multicolumn{2}{|l|}{ Diabetes } & $37.2 \%$ & $43 \%$ & 0.437 \\
\hline \multicolumn{2}{|c|}{ Pre-operation IABP*** use } & $4.7 \%$ & $2.3 \%$ & 0.682 \\
\hline \multicolumn{2}{|c|}{ The ankle circumference of the harvesting leg $(\mathrm{cm})$} & $23.66 \pm 2.58$ & $23.60 \pm 1.82$ & 0.841 \\
\hline
\end{tabular}

*OVH: Open Vein Harvesting, **EVH: Endoscopic Vein Harvesting, IABP: Intra-Aortic Balloon Pump

Table 2. Clinical outcome of the OVH and EVH groups in post-surgery intensive care units (ICU)

\begin{tabular}{|l|l|l|l|}
\hline Variable & OVH $(\mathrm{n}=86)$ & EVH $(\mathrm{n}=87)$ & $\mathrm{p}$-value \\
\hline $\begin{array}{l}\text { The ankle circumference of the harvesting leg, } \mathrm{cm} \\
(\text { Mean } \pm \text { SD) }\end{array}$ & $24.0 \pm 2.5$ & $24.1 \pm 2.0$ & 0.319 \\
\hline Pain score, (Mean \pm SD) & $2.0 \pm 1.6$ & $1.6 \pm 1.4$ & 0.058 \\
\hline Serum Albumin level, mg/dL (Mean \pm SD) & $3.2 \pm 0.4$ & $3.2 \pm 0.3$ & 0.514 \\
\hline Positive Troponin, $\mathrm{n}(\%)$ & 0 & 0 & - \\
\hline Serum Creatinine level, mg/dL (Mean \pm SD) & $1.1 \pm 0.7$ & $1.1 \pm 0.5$ & 0.691 \\
\hline Blood Pack cell infusion, n (\%) & $39(45.3 \%)$ & $33(37.9 \%)$ & 0.734 \\
\hline Cardiac arrhythmia & & & \\
\hline Premature ventricular contractions (PVCs), $\mathrm{n}(\%)$ & $11(12.7 \%)$ & $5(5.7 \%)$ & 0.115 \\
\hline Ventricular tachycardia (VT), $(\%)$ & $1(1.1 \%)$ & 0 & 0.494 \\
\hline Atrial Fibrillation (AF), n (\%) & $2(2.3 \%)$ & $1(1.1 \%)$ & 0.621 \\
\hline Cerebrovascular accident (CVA), n (\%) & 0 & 0 & - \\
\hline Intra-aortic Balloon Pump (IABP) use, $\mathrm{n}(\%)$ & $9(10.4 \%)$ & $8(8.6 \%)$ & 0.803 \\
\hline Re-operation & $3(3.5 \%)$ & $5(5.7 \%)$ & 0.720 \\
\hline Death, $\mathrm{n}(\%)$ & $3(3.5 \%)$ & $2(2.2 \%)$ & 0.619 \\
\hline
\end{tabular}

OVH: Open Vein Harvesting,EVH: Endoscopic Vein Harvesting 
Table 3. Clinical outcome of the OVH and EVH groups in post-surgery hospital stay in cardiac surgery ward

\begin{tabular}{|l|l|l|l|}
\hline Variable & OVH $(\mathrm{n}=83)$ & EVH $(\mathrm{n}=85)$ & $\mathrm{p}$-value \\
\hline $\begin{array}{l}\text { The ankle circumference of the harvesting leg, } \mathrm{cm} \\
\text { (Mean } \pm \text { SD) }\end{array}$ & $22.7 \pm 1.7$ & $23.2 \pm 1.6$ & 0.077 \\
\hline Pain score, (Mean \pm SD) & $1.6 \pm 1.3$ & $1.2 \pm 1.1$ & 0.003 \\
\hline Serum Albumin level, mg/dL (Mean \pm SD) & $3.2 \pm 0.4$ & $3.2 \pm 0.3$ & 0.514 \\
\hline Positive Troponin, $\mathrm{n}(\%)$ & 0 & 0 & - \\
\hline Serum Creatinine level, mg/dL (Mean \pm SD) & $1.7 \pm 0.8$ & $1.1 \pm 0.8$ & 0.922 \\
\hline Blood Pack cell infusion, $\mathrm{n}(\%)$ & 0 & 0 & 0 \\
\hline Cardiac arrhythmia & & & \\
\hline Premature ventricular contractions (PVCs), $\mathrm{n}(\%)$ & $1(1.2 \%)$ & 0 & 0.497 \\
\hline Ventricular tachycardia (VT), $(\%)$ & 0 & 0 & - \\
\hline Atrial Fibrillation (AF), $\mathrm{n}(\%)$ & $1(1.2 \%)$ & 0 & 0.497 \\
\hline Cerebrovascular accident (CVA), $\mathrm{n}(\%)$ & $1(1.2 \%)$ & 0 & 0.497 \\
\hline Intra-aortic Balloon Pump (IABP) use, $\mathrm{n}(\%)$ & 0 & 0 & - \\
\hline Re-operation & 0 & 0 & - \\
\hline Death, $\mathrm{n}(\%)$ & 0 & 0 & - \\
\hline Hospital Stay, day (Mean \pm SD) & $8.5 \pm 3.3$ & $8.4 \pm 3.2$ & 0.088 \\
\hline Hospital Stay Fee, Milion Tomman (Mean \pm SD) & $5.8 \pm 4.7$ & $7.3 \pm 2.0$ & 0.008 \\
\hline
\end{tabular}

OVH: Open Vein Harvesting, EVH: Endoscopic Vein Harvesting

\section{Discussion}

Abundant evidence has emerged in the recent years emphasizing that EVH is accompanied with a lower rate of legwound morbidity, better cosmetic results, and improved patient satisfaction $(1,8,9)$. Despite all such advantages, there are still certain concerns regarding the potential ability of this technique to damage the endothelial integrity of the vein (10). However, the results of our study showed that EVH did not cause any undesired clinical outcomes and the patients experienced less pain than the OVH group. In this study, the post-op pain score during the 6-week follow-up period in the EVH group was significantly less than the OVH group. In other similar studies that also have used the VAS for pain assessment, patients undergoing EVH rated their experience of pain on a 0-10 scale two points lower throughout the entire post-operative period and were pain-free a few days earlier than the OVH group $(5,11,12)$. Patients undergoing EVH due to experiencing less pain had shorter time to mobilization $(12,13)$. In the study by Cheng et al. (31), the rate of pain ( $23.1 \%$ vs. $6.7 \%)$, neuralgia $(24.3 \%$ vs. $7.1 \%)$, and patient satisfaction $(49 \%$ vs. $75 \%)$ were in a better status in the EVH than in the OVH group.

One of the other complications of vein harvesting is infection at the site of the incision. Various studies have indicated that the rate of infection in the OVH group varies between $2-25 \%$, resulting in significant clinical complications and additional costs to the healthcare system (3). In a meta-analysis by Athanasiou et al. of eleven RCTs, the EVH technique was associated with a significantly lower rate of infection at the harvesting site than OVH $(\mathrm{OR}=0.22, \mathrm{p}<0.00001)(15)$. In another meta-analysis including 35 studies, the EVH group again had a lower infection rate $(\mathrm{p}<0.0001)(16)$. In another study by Raja et al. in 2013 (3) on 411 CABG patients, the rate of infection at the harvesting site was followed up for four years. It was reported that the EVH technique almost eliminates the probability of infection at this site when compared to the OVH technique $(1.13 \%$ vs $1.3 \%, \mathrm{p}<0.001)$. The reason may be due to the smaller incision and the safe transfer of tissue in this surgical method. Another less important aspect may be due to preserved tissue perfusion and a lower likelihood of creating vital tissue flaps. However, the highlight of the current study was the zero infection rate in the 6-week follow-up period. This lower rate of infection in the EVH technique compared to OVH is of particular value in diabetic and obese patients and those with peripheral arterial diseases in whom EVH is considered the method of choice $(17,18)$. Irrespective of the harvesting site's infection rate, which has always been a major concern, complications related to the quality of the harvested vein, which, by closing the graft, can cause serious complications in other organs, is of great importance as well. In the current study the two groups were compared regarding heart, kidney, and cerebral complications during hospitalization, and there were no meaningful differences. Myocardial infarction (MI) is the most important complication, and it is an indicator of the graft's patency. In this study, similar to others, no difference was seen in the rate of MI in the short-term. In a meta-analysis by Satry et al. in 2013 (16) that included twelve studies and 3,872 
patients, no difference was reported in the rate of $\mathrm{MI}$ after the operation by either technique (SR risk: 0.87 ; $95 \% \mathrm{CI}$ : $0.68-1.11 ; \mathrm{p}=0.26)$.

One of the other important factors in estimating the safety of a certain technique is investigating the short-, mid- and long-term mortality. Our study showed no difference in mortality during hospitalization and the 6-week follow-up between the two groups. This also was reported in the few meta-analyses performed comparing EVH and OVH. Yet, more studies are required regarding this issue in order to obtain more precise results, especially in short- and midterm follow ups. Another important aspect of the current study is the therapeutic costs for which higher costs were achieved in the EVH group compared to OVH. It seems that this is mostly related to the cost of the technique itself. According to the few studies that have investigated this issue, it has been observed that the shorter time to ambulation and the lower rate of leg wound morbidity result in shortened hospital stay and lower medical costs in the EVH group (3). However, the two we studied showed no meaningful difference regarding the lengths of their hospital stays. Despite the increasing recognition of the benefits of the EVH technique, the quality of the harvested vein is still a major concern, because endothelial injury affects the graft opening following CABG. Studies in this respect have controversial results; Hussaini et al. reported no difference in the structural and functional viability of the saphenous vein endothelium between the EVH and OVH groups, yet they stated that the vasomotor function may decrease (19). Wang et al. also published similar results (20). Andreasen's study in 2015 showed that over the past 6.3 years, the majority of vein graft failures were significantly detected by EVH rather than OVH without any differences in long-term clinical outcomes (21). Angiographic follow-up results had no difference with clinical outcomes in cases with open versus endoscopic harvesting for coronary bypass surgery (23). The EVH is an ordinary technique to train for removing vein conduit in CABG (24). These findings led to increases in endoscopic vein harvesting $(\mathrm{EVH})$. Reduction in wound complications, satisfaction of recovery, shorter durations of admission, and reduced post-operative pain at the opening area after EVH have been reported when EVH and OVH were compared (24). The 2014 Society of Cardiology (ESC) and the European Association for Cardio-Thoracic Surgery (EACTS) Guidelines on Myocardial Revascularization addressed the methods of conduit harvest and issued a Class IIa Level A recommendation for EVH. This recommendation, which represents the first formal recommendation for EVH by ESC/EACTS, was based on data from meta-analyses as well as randomized trials, noting that nearly all studies documented reductions in wound infection and impaired healing, and the Guidelines also asserted that the most recent data do not demonstrate inferior clinical outcomes with EVH. The recommendation based on 2014 ESC/EACTS Guidelines about EVH is "Endoscopic vein harvesting should be considered to reduce the incidence of leg wound complications" (25). Moreover, in this study the vein grafts taken in the two groups showed no meaningful difference regarding their pathological findings $(\mathrm{p}=0.241)$.

This study had two main limitations. First, we could not do a post-operative control angiography or CT-angiography for evaluating the grafts patency, because there was no evidence of graft failure in our studied population. So, we were not able to publish the comparison of grafts patency between two groups of EVH and OVH. The second limitation was the short time of the follow-up. We recommend to the other researchers to compare the clinical outcomes of EVH and OVH over longer follow-up periods.

\section{Conclusions}

The findings of the current study revealed that the harvesting time is generally shorter in the EVH technique in contrast to several other studies. This discrepancy in the results may be due to the experience of the technicians and the equipment used for this purpose. A shorter harvesting time results in a shorter period of post-op care regarding leg-wound morbidity. It seems that we have once again illustrated an important link between minimally-invasive great saphenous vein harvesting and improved tissue healing when compared to conventional open surgery. However, additional research is required to investigate the cosmetic outcomes, hospital costs, and cost-efficiency further; more importantly, long-term graft patency should be investigated in the EVH technique. Taking into consideration the large number of CABG procedures performed in our region using the EVH technique, its training course should be further valued and emphasized to improve the quality of vein grafts besides causing minimal injury to the surrounding tissue.

\section{Acknowledgments:}

We thank Mr. Saeed Barati and Mr. Mohammad Reza Nadaf Kalateh for their assistance with this work. This study was supported financially by the Medical Faculty of Mashhad University of Medical Sciences. This manuscript resulted from Mr. Ahmad Amouzeshi's MD thesis. 


\section{Conflict of Interest:}

There is no conflict of interest to be declared.

\section{Authors' contributions:}

All authors contributed to this project and article equally. All authors read and approved the final manuscript.

\section{References}

1) Raja SG, Haider Z, Ahmad M, Zaman H. Saphenous vein grafts: to use or not to use? Heart, Lung and Circulation. 2004;13(2):150-6. Doi: 10.1016/j.hlc.2004.04.004, PMid: 16352226

2) Liliav B1, Yakoub D, Kasabian A. Necrotizing fasciitis following endoscopic harvesting of the greater saphenous vein for coronary artery bypass graft. JSLS. 2011 Jan-Mar;15(1):90-5. Doi: 10.4293/108680811X13022985131453, PMid: 21902951, PMCid: PMC3134705

3) Raja SG, Sarang Z. Endoscopic vein harvesting: technique, outcomes, concerns \& controversies. Journal of thoracic disease. 2013;5(Suppl 6):S630.

4) Rao C, Aziz O, Deeba S, Chow A, Jones C, Ni Z, et al. Is minimally invasive harvesting of the great saphenous vein for coronary artery bypass surgery a cost-effective technique? The Journal of thoracic and cardiovascular surgery. 2008;135(4):809-15. Doi: 10.1016/j.jtcvs.2007.09.042, PMid: 18374760

5) Coppoolse R, Rees W, Krech R, Hufnagel M, Seufert K, Warnecke H. Routine minimal invasive vein harvesting reduces postoperative morbidity in cardiac bypass procedures. Clinical report of 1400 patients. European Journal of Cardio-Thoracic Surgery. 1999;16(Supplement 2):S61-S6.

6) Raja SG, Siddiqui H, Ilsley CD, Amrani M. In-hospital outcomes of off-pump multivessel total arterial and conventional coronary artery bypass grafting: single surgeon, single center experience. The Annals of thoracic surgery. 2009;88(1):47-52. Doi: 10.1016/j.athoracsur.2009.04.013, PMid: 19559187

7) Egol K, Koval K, Zuckerman J, Koval K. Handbook of fractures. Fourth ed. Philadelphia: Wolters Kluwer/Lippincott Williams \& Wilkins Health; 2010 March 29, 2010.

8) Deppe A-C, Liakopoulos OJ, Choi Y-H, Slottosch I, Kuhn EW, Scherner M, et al. Endoscopic vein harvesting for coronary artery bypass grafting: a systematic review with meta-analysis of 27,789 patients. Journal of Surgical Research. 2013;180(1):114-24. Doi: 10.1016/j.jss.2012.11.013, PMid: 23218736

9) Andreasen JJ, Nekrasas V, Dethlefsen C. Endoscopic vs open saphenous vein harvest for coronary artery bypass grafting: a prospective randomized trial. European Journal of Cardio-Thoracic Surgery. 2008;34(2):384-9. Doi: 10.1016/j.ejcts.2008.04.028, PMid: 18508277

10) Lopes RD, Hafley GE, Allen KB, Ferguson TB, Peterson ED, Harrington RA, et al. Endoscopic versus open vein-graft harvesting in coronary-artery bypass surgery. New England Journal of Medicine. 2009;361(3):235-44. Doi: 10.1056/NEJMoa0900708, PMid: 19605828

11) Bonde P, Graham A, MacGowan S, editors. Endoscopic vein harvest: early results of a prospective trial with open vein harvest. The heart surgery forum; 2002.

12) Kiaii B, Moon BC, Massel D, Langlois $Y$, Austin TW, Willoughby A, et al. A prospective randomized trial of endoscopic versus conventional harvesting of the saphenous vein in coronary artery bypass surgery. The Journal of Thoracic and Cardiovascular Surgery. 2002;123(2):204-12. Doi: 10.1067/mtc.2002.118682, PMid: 11828277

13) Patel AN, Hebeler RF, Hamman BL, Hunnicutt C, Williams M, Liu L, et al. Prospective analysis of endoscopic vein harvesting. The American journal of surgery. 2001;182(6):716-9. Doi: 10.1016/S00029610(01)00824-8

14) Cheng D, Allen K, Cohn W, Connolly M, Edgerton J, Falk V, et al. Endoscopic vascular harvest in coronary artery bypass grafting surgery: a meta-analysis of randomized trials and controlled trials. Innovations: Technology and Techniques in Cardiothoracic and Vascular Surgery. 2005;1(2):61-74. Doi: 10.1097/01.gim.0000196316.48694.41

15) Athanasiou T, Aziz O, Skapinakis P, Perunovic B, Hart J, Crossman M-C, et al. Leg wound infection after coronary artery bypass grafting: a meta-analysis comparing minimally invasive versus conventional vein harvesting. The Annals of thoracic surgery. 2003;76(6):2141-6. Doi: 10.1016/S0003-4975(03)01435-8

16) Sastry P, Rivinius R, Harvey R, Parker RA, Rahm A-K, Thomas D, et al. The influence of endoscopic vein harvesting on outcomes after coronary bypass grafting: a meta-analysis of 267525 patients. European Journal of Cardio-Thoracic Surgery. 2013;44(6):980-9. Doi: 10.1093/ejcts/ezt121, PMid: 23515174

17) Allen KB, Heimansohn DA, Robison RJ, Schier JJ, Griffith GL, Fitzgerald EB, editors. Influence of endoscopic versus traditional saphenectomy on event-free survival: five-year follow-up of a prospective randomized trial. The heart surgery forum; 2003: Carden Jennings. 
18) Reed JF. Leg wound infections following greater saphenous vein harvesting: minimally invasive vein harvesting versus conventional vein harvesting. The international journal of lower extremity wounds. 2008;7(4):210-9. Doi: 10.1177/1534734608324172, PMid: 18815201

19) Hussaini BE, Lu XG, Wolfe JA, Thatte HS. Evaluation of endoscopic vein extraction on structural and functional viability of saphenous vein endothelium. J Cardiothorac Surg. 2011;6:82. Doi: 10.1186/17498090-6-82, PMid: 21663646, PMCid: PMC3125322

20) Wang H, Wu H, Jiang H, Wang Z, Potapov E, Stepanenko A. Initial experience with endoscopic saphenous vein harvesting for coronary artery bypass grafting in Chinese patients. The heart surgery forum. 2011 Oct;14(5):E291-6.

21) Andreasen JJ, Vadmann H, Oddershede L, Tilsted HH, Frøkjær JB, Jensen SE Decreased patency rates following endoscopic vein harvest in coronary artery bypass surgery.. Scand Cardiovasc J. 2015 Jul 1:1-7. [Epub ahead of print] PMID: 26053411

22) Van Diepen S1, Brennan JM, Hafley GE, Reyes EM, Allen KB, Ferguson TB, Peterson ED, Williams JB, Gibson CM, Mack MJ, Kouchoukos NT, Alexander JH, Lopes RD.Endoscopic harvesting device type and outcomes in patients undergoing coronary artery bypass surgery.Ann Surg. 2014 Aug;260(2):402, doi: 10.1097/SLA.0000000000000377. PMID: 24368640

23) Kim do Y1, Song H, Kim HW, Jo GH1, Kang J. Early Outcomes of Endoscopic Vein Harvesting during the Initial Learning Period. Korean J Thorac Cardiovasc Surg. 2015 Jun;48(3):174-9. doi: 10.5090/kjtcs.2015.48.3.174. Epub 2015 Jun 5. PMID: 26078923

24) Raja SG, Sarang Z. Endoscopic vein harvesting: technique, outcomes, concerns \& controversies.J Thorac Dis. 2013 Nov;5 Suppl 6:S630-7. doi: 10.3978/j.issn.2072-1439.2013.10.01. Review. PMID: 24251019

25) Kolh P, Windecker S, Alfonso F, Collet JP, Cremer J,Falk V,et al 2014 ESC/EACTS Guidelines on myocardial revascularization: the Task Force on Myocardial Revascularization of the European Society of Cardiology (ESC) and the European Association for Cardio-Thoracic Surgery (EACTS). Developed with the special contribution of the European Association of Percutaneous Cardiovascular Interventions (EAPCI).Eur J Cardiothorac Surg. 2014 Oct;46(4):517-92. doi: 10.1093/ejcts/ezu366. Epub 2014 Aug 29. PMID: 25173601. 